\title{
Conditions favoring retroactive interference between antecedent events (cue competition) and between subsequent events (outcome competition)
}

\author{
MARTHA ESCOBAR, FRANCISCO ARCEDIANO, and RALPH R. MILLER \\ State University of New York, Binghamton, New York
}

\begin{abstract}
Retrieval of a target association (A-B) is often impaired if training of a similar association is interpolated between target training and testing; this is known as retroactiveinterference. Two experiments, in which rats were used as subjects in a sensory preconditioning preparation, studied the associative nature of retroactive interference between antecedent events (i.e., $\mathrm{A}$ and $\mathrm{C}$ in the $\mathrm{A}-\mathrm{B}, \mathrm{C}-\mathrm{B}$ paradigm) and between subsequent events (i.e., $\mathrm{B}$ and $\mathrm{C}$ in the $\mathrm{A}-\mathrm{B}, \mathrm{A}-\mathrm{C}$ paradigm). With the present preparation, retroactive interference was equally strong between antecedent events and between subsequent events. Moreover, interference occurred only if (1) an association was trained in the interpolated phase and (2) the target and interpolated associations had a common element in a common temporal location.
\end{abstract}

Associative retroactive interference (impaired learning or retrieval of a target association [A-B] after interpolated training [e.g., A-C]) was first described in the verbal learning literature, and its analysis dominated associative research for many years (for reviews, see Britt, 1935; Slamecka \& Ceraso, 1960; Swenson, 1941). However, interest in associative interference effects has decreased in recent years. Moreover, contemporary learning theories (e.g., Mackintosh, 1975; Miller \& Matzel, 1988; Pearce \& Hall, 1980; Rescorla \& Wagner, 1972) assume that interference occurs only between antecedent events ${ }^{1}$ and then only if the interfering events are presented together at some point during training, rather than always separately, as in the traditional interference paradigms.

Recently, Bouton (1993) has proposed an associative model to account for interference between phasically trained subsequent events conditioned apart (i.e., the A-B, A-C paradigm). This retrieval-focused model suggests that retroactive interference phenomena, such as counterconditioning, in which $\mathrm{B}$ and $\mathrm{C}$ are stimuli that induce opposite effects (Sherrington, 1947), and extinction, in which C denotes the absence of B (Pavlov, 1927), arise from competition between memories for retrieval. In these situations, responding at test reflecting the target association $\mathrm{A}-\mathrm{B}$ is impaired by the subsequently acquired $\mathrm{A}-\mathrm{C}$ association. Bouton assumes that both associations are learned in a specific spatiotemporal context, and which association con-

Supportfor this research was provided by NIMH Grant 33881. We thank Raymond Chang, Daniel Choi, and Steven Stout for their comments on a preliminary version of this manuscript. Correspondence concerning this article should be addressed to R. R. Miller, Department of Psychology, SUNY-Binghamton, Binghamton, NY 13902-6000 (e-mail: rmiller@ binghamton.edu). trols behavior at test is determined by the test context-that is, which of the two associations is better primed (e.g., Neely, 1977) by the test context.

Matute and Pineño (1998b) reported interference between antecedent events (cues) paired in different phases with a common outcome (i.e., A-B, C-B), using a nonverbal task with human subjects. ${ }^{2}$ They found that this type of interference was context specific in that it would occur only if the interpolated training took place in the same context as testing. Matute and Pineño (1998b) extended Bouton's (1993) model to interference between antecedent events trained apart and concluded that this type of interference would occur whenever the interpolated association is better primed by the test context than is the target association. Thus, the $\mathrm{C}-\mathrm{B}$ association is better primed by the test context than is the A-B association (i.e., recency), the $\mathrm{A}-\mathrm{B}$ association is not retrieved when $\mathrm{A}$ is presented, and interference is evidenced. Escobar, Matute, and Miller (2001) provided a nonhuman analogue of Matute and Pineño's (1998b) results, demonstrating not only retroactive interference (i.e., A-B, A-C), but also proactive interference (i.e., A-C, A-B). Which type of interference was observed depended on which association (target or interpolated) was better primed at test, either by contextual or discrete cues.

One assumption made by Matute and Pineño (1998b) and Escobar et al. (2001) is that associations must have a common element for interference to occur. This is the case with both the A-B, A-C and the A-B, C-B paradigms. However, neither of these reports included groups in which the interpolated association had no elements in common with the target association (e.g., A-B, C-D). ${ }^{3}$ Similarly, these authors' claim that the same mechanism underlies interference between antecedent events and be- 
tween subsequent events has not been assessed (but see Pineño \& Matute, 2001). Indeed, these two types of retroactive interference differ appreciably. For example, Escobar et al. reported A-B, C-B interference (i.e., between antecedent events) only if neutral events (rather than emotionally charged events, such as footshock) were used as subsequent events. In contrast, $\mathrm{A}-\mathrm{B}, \mathrm{A}-\mathrm{C}$ interference (i.e., between subsequent events) has often been reported using emotionally charged stimuli (e.g., Pearce \& Dickinson, 1975). Thus, generalizations between the two paradigms may be inappropriate. Moreover, the situations frequently used to study interference between subsequent events are subject to criticism. Counterconditioning could reflect response rather than associative competition, and in extinction the absence of an event must be assumed to act as an interfering event. Interestingly, with nonhuman subjects, $\mathrm{A}-\mathrm{B}, \mathrm{A}-\mathrm{C}$ interference in the aforementioned paradigms has often been observed, whereas there are few demonstrations of $\mathrm{A}-\mathrm{B}, \mathrm{C}-\mathrm{B}$ interference. Thus, one might infer $\mathrm{A}-\mathrm{B}, \mathrm{A}-\mathrm{C}$ interference to be more robust than $\mathrm{A}-\mathrm{B}, \mathrm{C}-\mathrm{B}$ interference.

In the present experiments, equivalent situations were created to compare A-B, A-C and A-B, C-B interference by using only neutral stimuli during critical training. Moreover, we also assessed interference when the common element was changed from being the antecedent event in the target association to being the subsequent event in the interpolated association, and vice versa (i.e., $\mathrm{A}-\mathrm{B}, \mathrm{C}-\mathrm{A}$ and $\mathrm{A}-\mathrm{B}, \mathrm{B}-\mathrm{C})$. This allowed us to determine whether interference would occur whenever two associations simply have a common element or whether the common element must play a common temporal role (i.e., antecedent event or subsequent event) for interference to occur. Two control groups were included to provide a behavioral baseline for any potential Phase 2 extinction of the target association produced by presenting one of its elements without the other (e.g., A-C after A-B training, which degrades the A-B contingency). These groups were presented in the interpolated phase with the same events as were the groups listed above, but these events were not paired (i.e., $\mathrm{A}-\mathrm{B}, \mathrm{B} / \mathrm{C}$ and $\mathrm{A}-\mathrm{B}, \mathrm{C} / \mathrm{A}$, with " " representing explicitlyunpaired). (The explicitly unpaired condition is but one of the various control conditions that can be used in this situation. See Escobar et al., 2001, for studies that, with the same parameters, use additional control conditions.)

\section{EXPERIMENT 1}

Six groups of rats were each trained in Phase 1 with the A-B target association and exposed in Phase 2 to different treatments: $\mathrm{A}-\mathrm{C}$ (interference by an association with a common antecedent event), $\mathrm{C}-\mathrm{B}$ (interference by an association with a common subsequent event), C-A (interference by an associationin which the target antecedentevent served as a subsequent event), B-C (interference by an association in which the target subsequent event served as an antecedent event), $\mathrm{A} / \mathrm{C}$ (interference owing to the target antecedent event's being presented alone), or C/B (interference owing to the target subsequent event's being presented alone). Then, the subsequent event of the target association (B) was paired with an unconditioned stimulus (footshock) to allow for measurement of how Phase 2 treatment influenced A-B learning, as evidenced in conditioned responding to A (see Table 1). ${ }^{4}$

\section{Method}

\section{Subjects}

The subjects were 36 male and 36 female Sprague-Dawley, naive young adult rats, bred in our colony. The subjects were individually housed and maintained on a 16:8-h light:dark cycle; experimental sessions occurred midway through the light portion. The subjects had free access to food in the home cage. Prior to initiation of the ex-

Table 1

Design of Experiments 1 and 2

\begin{tabular}{lcccc}
\hline \multicolumn{1}{c}{ Group } & Phase 1 & Phase 2 & Phase 3 & Test \\
\hline Experiment 1 & & & & \\
A-Same & A-B & A-C & B-footshock & A \\
A-Diff & A-B & C-A & B-footshock & A \\
A-Unpaired & A-B & A/C & B-footshock & A \\
B-Same & A-B & C-B & B-footshock & A \\
B-Diff & A-B & B-C & B-footshock & A \\
B-Unpaired & A-B & B/C & B-footshock & A \\
Experiment 2 & & & & \\
A-Same & A-B & A-C & A-footshock & B \\
A-Diff & A-B & C-A & A-footshock & B \\
A-Unpaired & A-B & A/C & A-footshock & B \\
B-Same & A-B & C-B & A-footshock & B \\
B-Diff & A-B & B-C & A-footshock & B \\
B-Unpaired & A-B & B/C & A-footshock & B \\
\hline
\end{tabular}

Note-In group names, A and B refer to which stimulus served as the common element in the two interfering associations. Same, Diff, and Unpaired refer to the temporal location of the common element during Phase 2, relative to the temporal location of the common element during Phase 1 (same, different, or unpaired, respectively). A, B, and C were a click train, white noise, or complex tone, counterbalanced within groups. -, followed by. /, unpaired. 
periment, water availability was progressively reduced to $30 \mathrm{~min}$ per day, approximately $2 \mathrm{~h}$ after any scheduled treatment.

\section{Apparatus}

Twelve experimental chambers of two different types were used: six rectangular $(\mathrm{R})$ and six $\mathrm{V}$-shaped $(\mathrm{V})$. Chamber $\mathrm{R}$ was a clear Plexiglas enclosure, measuring $31.5 \times 8.25 \times 12.5 \mathrm{~cm}(1 \times \mathrm{w} \times \mathrm{h})$. The floor of Chamber $\mathrm{R}$ was constructed of $0.48-\mathrm{cm}$ diameter stainless steel rods, spaced $1.5 \mathrm{~cm}$ apart, center to center, which permitted delivery of constant-curren $t$ footshock. Chamber V was a 22.1$\mathrm{cm}$-long box in a vertically oriented truncated-V shape $(25.3 \mathrm{~cm}$ height, $21.3 \mathrm{~cm}$ wide at the top, $5.1 \mathrm{~cm}$ wide at the bottom). The floor and sides were constructed of stainless steel sheets, and the ceiling was clear Plexiglas. The floor consisted of two parallel metal plates, each $2.0 \mathrm{~cm}$ wide, with a $1.1-\mathrm{cm}$ gap between them, which permitted delivery of constant-current footshock.

Each chamber ( $\mathrm{R}$ and $\mathrm{V}$ ) was housed in separate dimly illuminated environmental isolation chests and was equipped with a waterfilled lick tube that extended $1 \mathrm{~cm}$ from the rear of a cylindrical niche, $4.5 \mathrm{~cm}$ in diameter, left-right centered in one short wall, with its axis perpendicular to the wall and positioned with its center $4.25 \mathrm{~cm}$ above the chamber's floor. Each niche had a horizontal infrared photobeam transversing it $1 \mathrm{~cm}$ in front of the lick tube. To drink from the tube, the subjects had to insert their heads into the niche, thereby breaking the photobeam. The amount of time the test stimulus caused the subjects to cease breaking the photobeam (interrupt drinking) served as our dependent variable.

Three speakers were mounted on different walls of each environmental chest. Each speaker could deliver a different auditory stimulus; a click train $(6 \mathrm{sec})$, complex tone $(800$ and $1000 \mathrm{~Hz}$ simultane- ously), and white noise, all $8 \mathrm{~dB}$ (C-scale) above the 74- $\mathrm{dB}$ (C-scale) background noise provided by a ventilation fan. During training, all conditioned stimuli (CSs) were $5 \mathrm{sec}$ in duration.

\section{Procedure}

The subjects were randomly assigned to one of six groups: A-Same, A-Diff, A-Unpaired, B-Same, B-Diff, and B-Unpaired ( $n \mathrm{~s}=12$ ), counterbalanced for sex. The designations $A$ and $B$ refer to which event of the target association, the antecedent (A) or the subsequent (B) event, served as the common element in the two associations. Same and Diff refer to whether the common element occupied the same or different temporal position in the target and interfering associations. Groups A-Unpaired and B-Unpaired received A-B training in Phase 1 and unpaired presentations of $\mathrm{A}$ and $\mathrm{C}$ or $\mathrm{B}$ and $\mathrm{C}$, respectively, in Phase 2.

The three auditory stimuli served as Events A, B, and C, counterbalanced within groups. The footshock was $1.0 \mathrm{~mA}$ for $0.5 \mathrm{sec}$. Chamber type ( $\mathrm{R}$ or $\mathrm{V}$ ) was counterbalanced within groups. All training sessions were $60 \mathrm{~min}$, unless otherwise noted.

Acclimation. On Day 1, all the subjects were acclimated to the experimental context. The subjects had access to the lick tubes, and no nominal stimuli were presented.

Phase 1: Target training. On Day 2, all the subjects received four A-B pairings with a mean intertrial interval of $14 \mathrm{~min}$. Termination of A coincided with onset of B. Lick tubes were unavailable.

Phase 2: Interpolated training. On Day 3, Groups A-Same, ADiff, B-Same, and B-Diff received four A-C, C-A, C-B, or B-C pairings, respectively, with a mean intertrial interval of 14 min (antecedent event termination coincided with subsequent event onset). Group A-Unpaired received four trials of each A and C, and Group

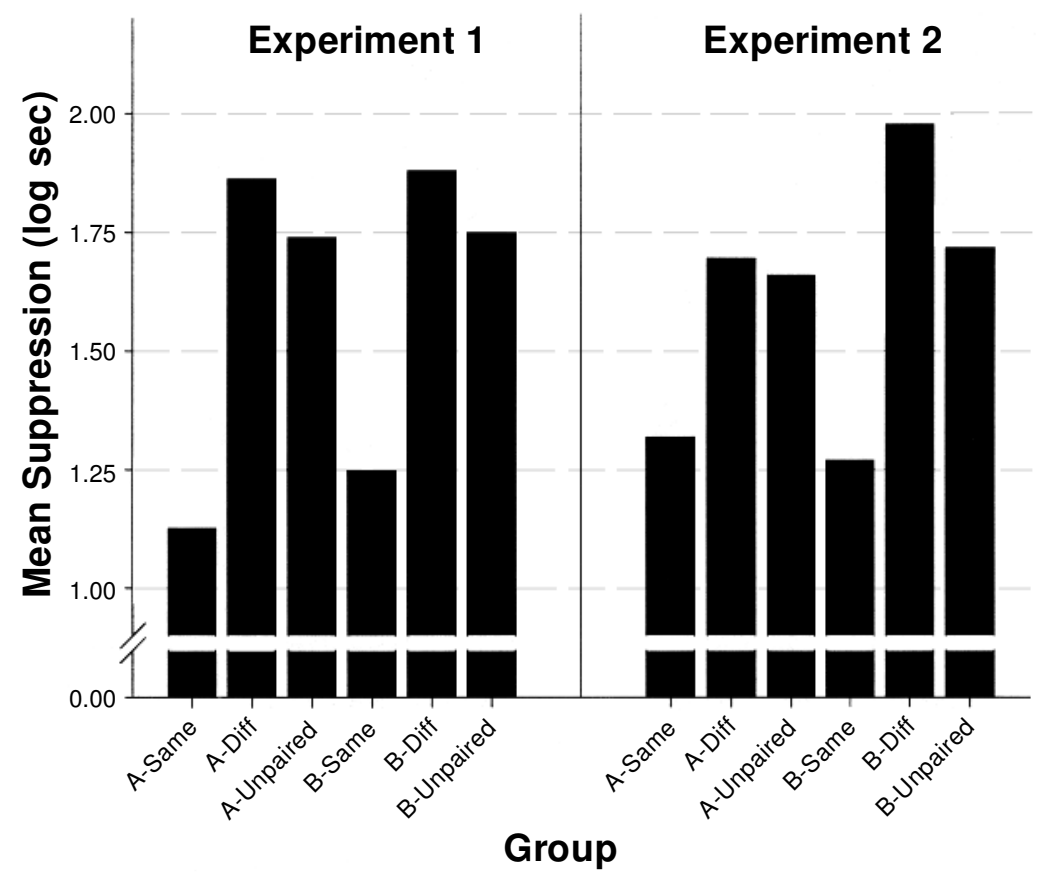

Figure 1. Mean times to complete 5 cumulative seconds of drinking in the presence of Stimulus A (Experiment 1) and Stimulus B (Experiment 2), adjusted for individual baseline scores. Unadjusted means $( \pm S E$ ) for Groups A-Same, A-Diff, AUnpaired, B-Same, B-Diff, and B-Unpaired were $1.11( \pm 0.10), 1.81( \pm 0.09), 1.77$ $( \pm 0.12), 1.28( \pm 0.13), 1.86( \pm 0.11)$, and $1.77( \pm 0.09)$ for Experiment 1 , and 1.30 $( \pm 0.13), 1.63( \pm 0.11), 1.57( \pm 0.09), 1.27( \pm 0.14), 2.01( \pm 0.15)$, and $1.82( \pm 0.13)$ for Experiment 2, respectively. The low scores in Groups A-Same and B-Same reflect retroactive interference between subsequent events and between antecedent events, respectively. 
B-Unpaired received four trials of each B and C, interspersed, with a mean intertrial interval of $7 \mathrm{~min}$. Lick tubes were unavailable.

Phase 3: First-order conditioning training. On Day 4, all the subjects received four $\mathrm{B}-$ footshock pairings, with a mean intertrial interval of $14 \mathrm{~min}$. Termination of B coincided with onset of the footshock. Lick tubes were unavailable.

Reacclimation. On Days 5 and 6, all the subjects were reacclimated to the experimental context to reestablish stable drinking behavior, which might have been disrupted by the footshock. The subjects had access to the lick tubes, and no nominal stimuli were presented. On Day 5, unusually high latencies to begin drinking were recorded; thus, all the animals were placed in the experimental context for an extra $30 \mathrm{~min}$, approximately $3 \mathrm{~h}$ after termination of their first reacclimation session.

Testing. On Day 7, all the subjects were tested for conditioned lick suppression to A. Time spent drinking by each subject upon placement in the test chamber was recorded. After 5 cumulative seconds of licking in the absence of any nominal stimulus (baseline scores), A was presented; thus, all the subjects were drinking at test stimulus onset. Time to complete 5 additional cumulative seconds of licking in the presence of A was recorded. The latter latencies presumably reflected the subjects' expectancy of the footshock following $\mathrm{A}$. The test session was $11 \mathrm{~min}$ in duration, and a ceiling score of 10 min was imposed on the time to complete 5 cumulative seconds of drinking in the presence of A.

All test scores were converted to log seconds (base 10), to better meet the assumptions of parametric statistical tests. Following the convention of our laboratory, all animals taking over $60 \mathrm{sec}$ to complete their baseline licking during testing were eliminated because such long latencies reflected unusual fear of the context (baseline criterion). One subject each from Groups A-Same and A-Diff met this baseline criterion. Because of the difficulties in reacclimation described above, all test scores were adjusted by use of individual baseline scores as a covariate. A two-tailed alpha level of .05 was adopted.

\section{Results and Discussion}

Strong conditioned responding was observed in the Diff and Unpaired conditions, whereas little responding was observed in either of the Same condition groups. Thus, with the present preparation, interference occurred between associations that had a common element, but only if this element had the same temporal location (i.e., antecedent or subsequent) in the two associations. Moreover, interference between antecedent events (i.e., the difference between Groups A-Same and A-Unpaired) was as strong as interference between subsequentevents (i.e., the difference between Groups B-Same and B-Unpaired; see Figure 1). The following analyses support these conclusions.

A 2 (common element, A vs. B) $\times 3$ (condition, same vs. different vs. unpaired) analysis of variance (ANOVA) performed on the baseline scores revealed no differences across groups $(F \mathrm{~s}<1)$. A similar $2 \times 3$ analysis of covariance (ANCOVA) conducted on the scores recorded during presentation of Test Stimulus A, using baseline scores as the covariate, revealed a main effect of condition $[F(2,63)=$ $\left.28.40, M S_{\mathrm{e}}=0.11\right]$, but no effect of common element $[F(1,63)<1]$, and no interaction $[F(2,63)<1]$. These results indicate that which events were presented during Phase 2 determined whether interference occurred, regardless of the common element being the antecedent (A) or the subsequent (B) event of the target association. A series of planned comparisons, using the ANCOVA's error term, was performed to further assess these conclusions.

Group A-Same differed from Group A-Unpaired $[F(1,63)=20.04]$, which reflects interference between subsequent events. In contrast, Group A-Diff did not differ from Group A-Unpaired $[F(1,63)<1]$. That is, even though the same events were presented during Phase 2 in Groups A-Same and A-Diff, significant interference occurred only if the common element (A) was the antecedent event in both associations. Supportive of this conclusion, Groups A-Same and A-Diff differed $[F(1,60)=27.75]$. A similar pattern of results emerged when the $B$ groups were analyzed. Group B-Same differed from Group B-Unpaired $[F(1,63)=14.08]$, which reflects interference between antecedent events. Groups B-Diff and B-Unpaired did not differ $[F(1,63)<1]$, but Groups B-Same and B-Diff differed $[F(1,63)=22.19]$. Thus, significant interference between antecedentevents occurred if the subsequent event of the target association was also the subsequent event of the interfering association, but not if its temporal location was changed in the interfering association. The nonsignificance of common element (antecedent vs. subsequent) was further confirmed by comparing Groups A-Same and B-Same, A-Diff and B-Diff, and A-Unpaired and B-Unpaired $\left[F_{\mathrm{S}}(1,60)<1\right]$.

In conclusion, interference occurred whenever the common element maintained the same temporal location (i.e., antecedent or subsequent) in the two associations, but not if its temporal location was changed between the target and the interfering training. With our parameters, interference between antecedent events and interference between subsequent events were approximately equal. Moreover, the difference between the Same and the Unpaired conditions suggests that our interference treatment resulted in an attenuation of responding that was not exclusively due to degrading the A-B contingency by presenting either A (Condition A) or B (Condition B) alone during Phase 2.

\section{EXPERIMENT 2}

A potential problem with Experiment 1 is that the $\mathrm{B}-$ footshock pairings of Phase 3 resulted in dissimilar treatments across conditions. For example, Event $B$ was presented only in one phase in the A-B, A-C situation, whereas it was the common element in the A-B, C-B situation. Moreover, testing on Event A meant that some groups were tested on the common element (e.g., A-B, A-C), whereas other groups were tested on an element presented only in one phase of treatment (e.g., A-B, C-B). One could prevent these potential confounds by pairing in all conditions the common element with footshock and then testing on the remaining element of the target association. However, this would result in testing for a forward association in some cases (e.g., the A-B association in the A-B, C-B situation) and for a backward association in other cases (e.g., the $\mathrm{B}-\mathrm{A}$ association in the $\mathrm{A}-\mathrm{B}, \mathrm{A}-\mathrm{C}$ situation). To determine whether the results of Experiment 1 were due to the potential confounds described above, Experiment 2 used the 
same design as that in Experiment 1, with the difference that the antecedent event of the target association, A, was paired with footshock following interference treatment and testing occurred with B. ${ }^{5}$

\section{Method}

\section{Subjects, Apparatus, and Procedure}

The subjects were 36 male and 36 female Sprague-Dawley, naive adult rats, bred in our colony, maintained as in Experiment 1. The apparatus and procedure were identical to those in Experiment 1, except that (1) in Phase 3, A (rather than B) was paired with footshock and (2) testing was on B (rather than on A; see Table 1).

As in Experiment 1, all animals received one 60-min and one 30min reacclimation session on Day 5 and test scores were adjusted for individual baseline scores. One subject from Group A-Diff met the baseline criterion for elimination. Data from 1 subject from each of Groups A-Diff and B-Same were lost owing to experimenter error.

\section{Results and Discussion}

Experiment 2 replicated the results of Experiment 1. Interference was observed in both the antecedent and the subsequent conditions, but only if the common element had the same temporal location in the two associations (see Figure 1). The following analyses support these conclusions.

A 2 (common element, A vs. B) $\times 3$ (condition, same vs. different vs. unpaired) ANOVA performed on baseline scores revealed no differences between groups (all $p \mathrm{~s}>.10$ ). A similar $2 \times 3$ ANCOVA conducted on the scores recorded during presentation of test stimulus $\mathrm{B}$, using baseline scores as the covariate, revealed a main effect of condition $\left[F(2,62)=12.47, M S_{\mathrm{e}}=0.14\right]$, but no effect of common element $\left[F(1,62)=1.09, M S_{\mathrm{e}}=0.14, p=.30\right]$, and no interaction $\left[F(2,62)=1.11, M S_{\mathrm{e}}=0.14, p=.34\right]$. Planned comparisons revealed interference both between subsequent events and between antecedent events, provided the common element had the same temporal location in the two associations [Groups A-Same vs. A-Unpaired and Groups B-Same vs. B-Unpaired, $F \mathrm{~s}(1,62)=4.89$ and 7.92 , respectively]. In contrast, interference was not observed if the temporal location of the common element was changed between Phases 1 and 2 [Groups A-Diff vs. A-Unpaired, $F(1,62)<1$, and Groups B-Diff vs. B-Unpaired, $F(1,62)=$ $2.82, p=.10]$. As in Experiment 1, Groups A-Same and ADiff and Groups B-Same and B-Diff differed $\left[F_{\mathrm{S}}(1,62)=\right.$ 5.46 and 20.10, respectively]. The lack of an effect of common element (antecedent vs. subsequent) was further analyzed by comparing Groups A-Same and B-Same, A-Diff and B-Diff, and A-Unpaired and B-Unpaired. All these comparisons were not significant ( $p s>.05$ ), suggesting that, with the present parameters, interference between antecedent events and interference between subsequent events were approximately equal.

\section{GENERAL DISCUSSION}

These studies demonstrate, in a sensory-preconditioning preparation, retroactive interference between antecedent events trained apart (A-B, C-B ) and between subsequent events trained apart $(\mathrm{A}-\mathrm{B}, \mathrm{A}-\mathrm{C})$. With this preparation, retroactive interference between antecedent events was as strong as that between subsequent events. A common element between the interfering associations appears to be necessary for interference to occur; however, this common element must also have the same temporal location (i.e., antecedent or subsequent) in the two associations. That is, there was no significant interference when training took the form $\mathrm{A}-\mathrm{B}, \mathrm{B}-\mathrm{C}$ or $\mathrm{A}-\mathrm{B}, \mathrm{C}-\mathrm{A}$.

Our design shares many aspects with some experiments within the verbal learning tradition, which investigated whether paired-associate learning would simultaneously create forward (stimulus-response) and backward (responsestimulus) associations (i.e., the principle of associative symmetry; Asch \& Ebenholtz, 1962). Some of these studies used the A-B, A-C paradigm, which was assumed to result in interference between stimulus-response associations, and the A-B, C-B paradigm, which was assumed to result in interference between response-stimulus associations. Other studies attempted to strengthen one association over the other by varying the temporal location of the stimulus and the response; that is, they used the A-B, B-C paradigm to make the stimulus-response association stronger than the response-stimulus association and the $\mathrm{A}-\mathrm{B}, \mathrm{C}-\mathrm{A}$ paradigm to make the response-stimulus association stronger than the stimulus-response association. A review of studies using these four paradigms yields conflicting results. For example, Johnston (1969) and Petrich (1970) observed interference in the A-B, A-C and A-B, $\mathrm{C}-\mathrm{A}$ paradigms if a forward (but not a backward) test was used (i.e., if at test, subjects were cued with A to retrieve B), and interference in the $\mathrm{A}-\mathrm{B}, \mathrm{C}-\mathrm{B}$ and $\mathrm{A}-\mathrm{B}, \mathrm{B}-\mathrm{C}$ paradigms if a backward (but not a forward) test was used (i.e., if subjects were cued with B to retrieve A). In contrast, Keppel, Bonge, Strand, and Parker (1971) observed interference in all four paradigms, with both forward and backward testing, provided that the target association was learned only to a $50 \%$ criterion. Inconsistent with these results, we failed to observe interference with both the A-B, $\mathrm{C}-\mathrm{A}$ and the $\mathrm{A}-\mathrm{B}, \mathrm{B}-\mathrm{C}$ paradigms (Condition Diff), relative to the unpaired control groups. Perhaps if we had used the same control condition as the verbal learning experiments described above (i.e., an A-B, C-D paradigm), interference would have occurred in Condition Diff. However, even if interference had occurred in those groups, such interference would have been less than that in the Same groups, and it would not have differed from decrements in responding caused by the unpaired treatment (i.e., degraded contingency), which the above cited verbal learning studies omitted.

Although inconsistent with the verbal learning reports described above, the data reported here appear consistent with theories that assume that time is encoded as part of all associations. For example, the temporal coding hypothesis (Matzel, Held, \& Miller, 1988; Savastano \& Miller, 1998) can be extended to suggest that maximal interfer- 
ence will occur when two associations share a common element in a common temporal location (i.e., antecedent or subsequent). According to this theory, all associations are represented as temporal maps (Honig, 1981) in memory. In the A-B, A-C case, two maps are formed, A $\rightarrow$ B, and $\mathrm{A} \rightarrow \mathrm{C}$. (The arrows represent the temporal location of the event [e.g., A precedes B]; however, the temporal coding hypothesis assumes that the events can be retrieved in either direction [i.e., the animal encodes both that $\mathrm{A}$ precedes B and that B follows A].) Because these maps have a common element, the two can be integrated into a common map, $\mathrm{A} \rightarrow(\mathrm{B}$ and $\mathrm{C})$. In the $\mathrm{A}-\mathrm{B}, \mathrm{B}-\mathrm{C}$ case, integration results in $\mathrm{A} \rightarrow \mathrm{B} \rightarrow \mathrm{C}$. If one assumes that two representations in the same temporal location within a temporal map interfere with one another more than the same two representations at different temporal locations, greater interference should be observed in the A-B, A-C, than in the A-B, B-C case. Note that this is an extension of the mechanisms proposed by the temporal coding hypothesis. Unless priming principles are incorporated (e.g., Escobar et al., 2001), the hypothesis has no mechanism to predict whether responding should be greater to $\mathrm{B}$ or $\mathrm{C}$ in the $\mathrm{A}-\mathrm{B}, \mathrm{A}-\mathrm{C}$ paradigm.

An important implication of the present results is that retroactive interference between subsequent events (Group A-Same) reflects associative competition, rather than response competition. As was previously mentioned, the A-B, A-C case has traditionally been studied in paradigms such as counterconditioning,in which $\mathrm{B}$ and $\mathrm{C}$ represent outcomes of opposite motivational values (e.g., food and footshock), which elicit opposite types of responding (approach and withdrawal). In our situation, the interfering associations consisted of neutral elements; only one emotionally charged outcome was introduced, and then only after interference training. Thus, response competition is not an issue here. Moreover, interference was observed even when the common element was paired with footshock, a result that seemingly can be explained only by associative interference.

The attenuated responding observed in Groups A-Same and B-Same did not result from degraded contingency. In Phase 2, Groups A-Unpaired and B-Unpaired (as well as Groups A-Diff and B-Diff) received presentations of A without $B$ or $B$ without $A$, which equally decreased the A-B contingency of Phase 1 . Thus, training an interpolated association has a more deleterious effect on responding to the target (A-B) association than does partially degrading the $\mathrm{A}-\mathrm{B}$ contingency.

Matute and Pineño (1998a) suggested that retroactive interference between antecedent events and between subsequent events could be integrated into one theoretical framework by hypothesizing that retroactive interference will occur whenever the interpolated association is better primed by the test context than is the target association. Escobar et al. (2001) extended Matute and Pineño's (1998a) assumptions to incorporate proactive interference effects and found that responding to one association was attenuated whenever the other association was better primed by the test context. The present results further extend these findings and suggest that greatest interference occurs between associations that have a common element in a common temporal location. This series also demonstrates equivalent retroactive interference between antecedent events and between subsequent events, using highly similar situations, and hence supports the notion that a single mechanism underlies both types of interference. The priming notion suggested by Bouton (1993) and extended by Matute and Pineño (1998a) and Escobar et al. currently provides a plausible mechanism to account for these interference effects.

\section{REFERENCES}

ABra, J. C. (1967). Time changes in the strength of forward and backward associations. Journal of Verbal Learning \& Verbal Behavior, 6 , 640-645.

Asch, S. E., \& Ebenholtz, S. M. (1962). The principle of associative symmetry. Proceedings of the American Philosophical Society, 106, 135-163.

Bouton, M. E. (1993). Context, time, and memory retrieval in the interference paradigms of Pavlovian learning. Psychological Bulletin, 114, 80-99.

BrITT, S. H. (1935). Retroactive inhibition: A review of the literature. Psychological Bulletin, 32, 381-440.

Cheung, C. G., \& Goulet, L. R. (1968). Retroactive inhibition of R-S associations in the A-B, B-C, C-B paradigms. Journal of Experimental Psychology, 76, 321-322.

Cole, R. P., Barnet, R. C., \& Miller, R. R. (1995). Temporal encoding in trace conditioning. Animal Learning \& Behavior, 23, 144-153.

Escobar, M., Matute, H., \& Miller, R. R. (2001). Cues trained apart compete for behavioral control in rats: Convergence with the associative interference literature. Journal of Experimental Psychology: General, 130, 97-115.

Heth, C. D. (1976). Simultaneous and backward fear conditioning in the rat. Journal of Experimental Psychology: Animal Behavior Processes, 2, 117-129.

Honig, W. K. (1981). Working memory and the temporal map. In N. E. Spear \& R. R. Miller (Eds.), Information processes in animals: Memory mechanisms (pp. 167-197). Hillsdale, NJ: Erlbaum.

Johnston, W. A. (1968). Bidirectional interference in an A-B, C-B paradigm. Journal of Verbal Leaning \& Verbal Behavior, 7, 305-311.

JoHnston, W. A. (1969). The directionality of transfer and unlearning. Journal of Verbal Learning \& Verbal Behavior, 8, 581-590.

Keppel, G., Bonge, D., Strand, B. Z, \& Parker, J. T. (1971). Direct and indirect interference in the recall of paired associates. Journal of Experimental Psychology, 88, 414-422.

Mackintosh, N. J. (1975). A theory of attention: Variations in the associability of stimuli with reinforcement. Psychological Review, 82, 276-298.

Matute, H., \& Pineño, O. (1998a). Cue competition in the absence of compound training: Its relation to paradigms of interference between outcomes. In D. L. Medin (Ed.), The psychology of learning and motivation (Vol. 38, pp. 45-81). San Diego: Academic Press.

Matute, H., \& Pineño, O. (1998b). Stimulus competition in the absence of compound conditioning. Animal Learning \& Behavior, 26, 3-14.

Matzel, L. D., Held, F. P., \& Miller, R. R. (1988). Information and expression of simultaneous and backward associations: Implications for contiguity theory. Learning \& Motivation, 19, 317-344.

Miller, R. R., \& MATZEL, L. D. (1988). The comparator hypothesis: A response rule for the expression of associations. In G. H. Bower (Ed.), The psychology of learning and motivation (Vol. 22, pp. 51-92). San Diego: Academic Press.

NeELy, J. H. (1977). Semantic priming and retrieval from lexical memory: Roles of inhibitionless spreading activation and limited-capacity attention. Journal of Experimental Psychology: General, 106, 226-254.

Pavlov, I. P. (1927). Conditioned reflexes (G. V. Anrep, Trans.) London: Oxford University Press. 
Pearce, J. M., \& Dickinson, A. (1975). Pavlovian counterconditioning: Changing the suppressive properties of shock by association with food. Journal of Experimental Psychology: Animal Behavior Processes, 104, 170-177.

Pearce, J. M., \& Hall, G. (1980). A model for Pavlovian learning: Variations in the effectiveness of conditioned but not of unconditioned stimuli. Psychological Review, 87, 532-552.

Petrich, J. A. (1970). S-R and R-S unlearning as a function of transfer paradigm. Journal of Experimental Psychology, 83, 19-24.

Pineño, O., \& MATUte, H. (2001). Further evidence on the similarities between interference between cues and between outcomes. Manuscript submitted for publication.

Rescorla, R. A., \& WAgner, A. R. (1972). A theory of Pavlovian conditioning: Variations in the effectiveness of reinforcement and nonreinforcement. In A. H. Black \& W. F. Prokasy (Eds.), Classical conditioning II: Current theory and research (pp. 64-99). New York: Appleton-Century-Crofts.

Savastano, H. I., \& Miller, R. R. (1998). Time as content in Pavlovian conditioning. Behavioural Processes, 44, 147-162.

Sherrington, C. S. (1947). The integrative action of the central nervous system. Cambridge: Cambridge University Press.

Slamecka, N. J., \& Ceraso, J. (1960). Retroactive and proactive inhibition of verbal learning. Psychological Bulletin, 57, 449-475.

SwENSOn, E. J. (1941). Retroactive inhibition: A review of the literature (University of Minnesota Studies in Education, Vol. 1). Minneapolis: University of Minnesota Press.

Ward-Robinson, J., \& HALl, G. (1996). Backward sensory preconditioning. Journal of Experimental Psychology: Animal Behavior Processes, 22, 395-404.

WARD-Robinson, J., \& HALL, G. (1998). Backward sensory preconditioning when reinforcement is delayed. Quarterly Journal of Experimental Psychology, 51B, 349-362.

\section{NOTES}

1. The terms antecedent and subsequent event refer to the temporal position of the event in the dyadic association. For example, in the A-B case, in which A is followed by B, A is the antecedent event and B is the subsequent event.

2. Although Matute and Pineño (1998b) were the first to describe A-B, C-B interference in a Pavlovian preparation, this type of interference has long been studied within the verbal learning literature (e.g., Abra, 1967; Cheung \& Goulet, 1968; Johnston, 1968).

3. Notably, there are reports of interference when using the A-B, C-D paradigm. Nonetheless, such interference generally has been considered to be so weak that the A-B, C-D paradigm has often been used as a control for interference in the other paradigms.

4. The use of neutral stimuli during target training and pairing of one of those stimuli with an emotionally charged outcome after target training is known as sensory preconditioning and is a procedure commonly used in nonhuman preparations to avoid potential complications that may result from the use of emotionally charged stimuli during interference treatment (see Escobar et al., 2001, for a discussion of this issue).

5. Pairing A with footshock and testing on B is essentially a backward sensory preconditioning procedure in which responding to B was expected on the basis of prior work in our (e.g., Cole, Barnet, \& Miller, 1995) and other (e.g., Ward-Robinson \& Hall, 1996, 1998) laboratories. To increase the likelihood of observing responding to B after backward sensory preconditioning, the parameters used for Experiment 2 (and 1) were selected to maximize excitatory stimulus control by a backwardtrained CS (i.e., a low number of trials; Heth, 1976).

(Manuscript received September 21, 2000; revision accepted for publication March 8, 2001.) 